\title{
The Interdiffusion Modeling of Aluminide Coated Ti-47Al-2Cr-2Nb-0.5Zr-0.5Y Intermetallic Alloy
}

\author{
F. Muhammad ${ }^{1 *}$, E. A. Basuki ${ }^{1}$, M. I. Juliansyah ${ }^{1}$ \\ ${ }^{I}$ Department of Metallurgical Engineering, Institut Teknologi Bandung, \\ $\mathrm{Jl}$. Ganesha 10, Bandung 40132, Indonesia
}

Received: 29 May 2015, Revised: 20 July 2015, Accepted: 30 July 2015

\begin{abstract}
In the present study, the interdiffusion behavior between coating layer and substrate of aluminide coated Ti$47 \mathrm{Al}-2 \mathrm{Cr}-2 \mathrm{Nb}-0.5 \mathrm{Zr}-0.5 \mathrm{Y}$ intermetallic alloy were investigated at $800^{\circ} \mathrm{C}, 900^{\circ} \mathrm{C}$, and $1000^{\circ} \mathrm{C}$ under argon atmosphere (closed system). The pack cementation, consists of 20\%-wt. Al, 2\%-wt. $\mathrm{NH}_{4} \mathrm{Cl}$, and $78 \%$-wt. $\mathrm{Al}_{2} \mathrm{O}_{3}$, was carried out at $900^{\circ} \mathrm{C}$ for 10 hours. The phases in the coatings, interdiffusion layer, and substrate were examined using optical microscope and scanning electron microscope (SEM) while the chemical composition were examined by Energy Dispersive X-Ray Spectroscopy (EDS) attached on the SEM. The interdiffusion coefficients were calculated according to Boltzmann-Matano method using the data obtained from EDS analyses. The calculated interdiffusion coefficients are $7.091 \times 10^{-14}, 1.650 \times 10^{-12}$, and $5.261 \times 10^{-12} \mathrm{~cm}^{2} / \mathrm{s}$ respectively for $800^{\circ} \mathrm{C}, 900^{\circ} \mathrm{C}$, and $1000^{\circ} \mathrm{C}$. The analytical and numerical method were proposed in this study to quantitatively predict the concentration profiles between coating layer, interdiffusion layer, and substrate. A reasonable agreement has been achieved between the experimental results and the simulated concentration profiles at every temperatures.
\end{abstract}

Keywords: coating, interdiffusion, intermetallic, pack aluminizing, titanium aluminide

\section{INTRODUCTION}

The TiAl intermetallic alloys have been attracted considerable interest due to low density and excellent mechanical properties at high temperatures application [1-3]. Therefore, they are being considered as replacement of some Ni-based superalloys [4]. However, the oxidation and corrosion resistance of this intermetallic alloy decrease significantly at temperature above $800^{\circ} \mathrm{C}$. There are two methods that generally used to overcome this problem, i.e., (i) by adding the elements that increase oxidation resistance of TiAl intermetallic alloys, such as chromium, and (ii) by applying aluminide coating at the surface of the alloys [5]. However, the addition of alloying element is practically not enough and also may have a negative effect on the mechanical properties of the material. Therefore, aluminide based coatings are thought to be more attractive [6].

The stability of aluminide coating is affected by: (i) selective oxidation and hot-corrosion

Corresponding author.

E-mail address: fadhlim91@gmail.com processes; and (ii) interdiffusion between the coating layer and the substrate. Each of these degradation process has a negative effect on the coating structure during its service life and on its ability to protect the alloy component [5].

In the present study, the interdiffusion behavior of Ti-47Al-2Cr-2Nb-0.5Zr-0.5Y intermetallic alloy was investigated. The interdiffusion coefficient was calculated from the experimental data. It was then used to generate the concentration profiles between coating layer, interdiffusion layer, and the substrate.

\section{MODEL CALCULATION}

The interdiffusion coefficients for each temperature were calculated according to Boltzmann-Matano method using the data obtained from EDS analyses. The calculated interdiffusion coefficients were then substituted to error function equation as follows.

$$
\frac{C_{x}-C_{0}}{C_{S}-C_{0}}=1-e r f\left(\frac{x}{2 \sqrt{\widetilde{D} t}}\right)
$$

where $C_{x}$ refers to concentration at $x$ distance, $t$ refers to time, $C_{0}$ refers to concentration at infinite 
distance, $C_{s}$ refers to concentration at $x=0$, and refers to diffusivity. This equation was then used to generate analytical solution.

The model was also generated by numerical solution using explicit finite difference method by macro visual basic programming tools contained in

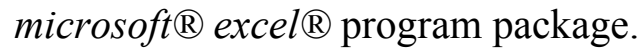

By using explicit finite difference method, $C(x, t)$ can be determined using followed calculation prosedure.

$$
C(i+1, j)=\frac{C(i, j+1)+(M+2) * T(i, j)+T(i, j-1)}{M}
$$

Later, in order to get convergent and stable calculation, the value of $M$ should be $\geq 2$ or $(1 / M)$ $\leq 1 / 2$ so-called "stability criteria". To meet this criteria, the value of $\Delta t$ and $\Delta x$ need to be adjusted. The generated model was then validated by comparing the experimental results and the simulated calculation.

\section{EXPERIMENTAL METHOD}

The TiAl intermetallic alloy with chemical composition of Ti-47Al-2Cr-2Nb-0.5Zr- $0.5 \mathrm{Y}$ was produced by melting the high purity titanium and aluminum using an electric arc furnace (EAF-DC) under high purity argon atmosphere. The buttons of the materials were further homogenized by heating in a tube furnace at $1100^{\circ} \mathrm{C}$ for 10 hours in argon atmosphere. The as homogenized substrate was cut to obtain several samples in a dimension of $7 \times 7 \times$ $2 \mathrm{~mm}$ using wire cutter. The samples were polished by abrasive paper and cleaned by ultrasonic cleaner. This sample will be used as substrate for pack aluminizing.

The prepared pack was mixed of $20 \%$-wt aluminium powder, $2 \%$-wt activator $\mathrm{NH}_{4} \mathrm{Cl}$, and $78 \%$-wt $\mathrm{Al}_{2} \mathrm{O}_{3}$. The pack filler was dried first in an oven at $110^{\circ} \mathrm{C}$ for 24 hours to exclude the moisture. The pack materials, retort, and samples were put into an argon box. Argon gas was then flowed for \pm $100 \mathrm{ml} /$ minute and leave for 15 minutes to purge the air out from argon box. The pack materials were mixed thoroughly for 15 minutes and the samples were inserted into the retort made from alumina, closed with the lid, and sealed with alumina cement.

Retort that has been filled with pack materials and samples were inserted into tube furnace. Argon was flowed with the rate of $10 \mathrm{~mL} /$ minutes for 10 minutes to purge the air. Coating was done by pack aluminizing method at $900^{\circ} \mathrm{C}$ for 10 hours. After 10 hours, the furnace was turned off and the argon was kept flowed until the temperature reached room temperature. The retort was then taken out of furnace, washed by water and cleaned by ultrasonic cleaner.
The aluminide coated samples were then inserted into tube furnace and heated under high purity argon atmosphere at $800^{\circ} \mathrm{C}$, $900^{\circ} \mathrm{C}$, and $1000^{\circ} \mathrm{C}$, respectively, for 5,10 , and 22 hours, followed by quenching in water. After standard metallographic preparation, the phases in the coatings and interdiffusion layers were examined by optical and scanning electron microscopy (SEM), while chemical composition of the coating and phases were examined with EDS attached on the SEM.

\section{RESULTS AND DISCUSSION}

The metallography analysis of as coated specimen is shown in Fig. 1. The EDS analyses on aluminide coating layer show that the composition of $\mathrm{Al}$ is $75.14 \%$ which is appropriate with $\mathrm{Al}$ composition on $\mathrm{TiAl}_{3}$ phase. The thickness of the $\mathrm{TiAl}_{3}$ layer are varied between $64-88 \mu \mathrm{m}$.

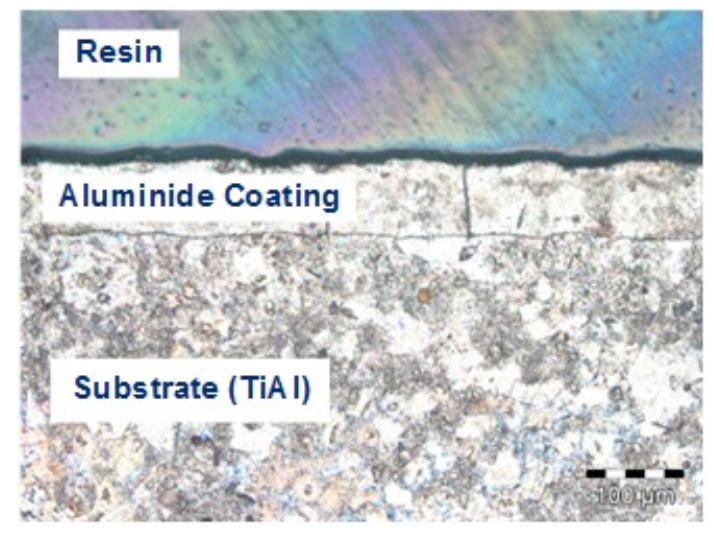

Fig. 1. As coated microstructure.

By using Boltzmann-Matano method and steps that have been described previously, the calculated interdiffusion coefficients for each temperature is shown in Table 1.

Table 1. The calculated interdiffusion coefficients using Boltzmann-Matano Method

\begin{tabular}{cc}
\hline Temperature $\left({ }^{\circ} \mathrm{C}\right)$ & Interdiffusion Coefficients $(\mathrm{D}) \mathrm{cm}^{2} / \mathrm{s}$ \\
\hline 800 & $7.091 \times 10^{-14}$ \\
900 & $1.650 \times 10^{-12}$ \\
1000 & $5.261 \times 10^{-12}$
\end{tabular}

It appears from the table that the interdiffusion coefficient increase exponentially along with the increase of temperature. Therefore, the interdiffusion rate would be faster as the temperature increase.

The microstructures with the simulated concentration profiles and experimental results of interdiffusion at $800^{\circ} \mathrm{C}, 900^{\circ} \mathrm{C}$, and $1000^{\circ} \mathrm{C}$ are given in Fig.2, Fig. 3, and Fig. 4 respectively. It can be seen from the picture that at the same heating 
time, the interdiffusion layer would be thicker with the increase of temperature.

The depletion of the coating layer occurs due to the diffusion of aluminum atoms in coating layer through the substrate, the aluminum content in the coating layer continuously decrease as the heating process carried out. On the other hand, the aluminum content at the interface of coating layersubstrate will be increased and form $\mathrm{TiAl}_{2}$ phase. The amount $\mathrm{TiAl}_{2}$ phase then increase with the time. The coalescence of $\mathrm{TiAl}_{2}$ phase would produce a continuous layer of $\mathrm{TiAl}_{2}$ or interdiffusion layer.

As the interdiffusion layer formed, the interdiffusion process further takes place in two stages. In the first stage, interdiffusion occurs from the coating layer through the interdiffusion layer. While in the second stage, interdiffusion occurs from the interdiffusion layer through the substrate.

Since the $\mathrm{TiAl}_{3}$ phase has higher diffusivity than $\mathrm{TiAl}_{2}$ phase, the rate of interface movement of $\mathrm{TiAl}_{3} / \mathrm{TiAl}_{2}$ is faster than the interface movement of $\mathrm{TiAl}_{2} /$ substrate. As a consequence, the coating layer will rapidly decrease and further depleted while the interdiffusion layer will be thicker. In other words, the coating layer is degradated.
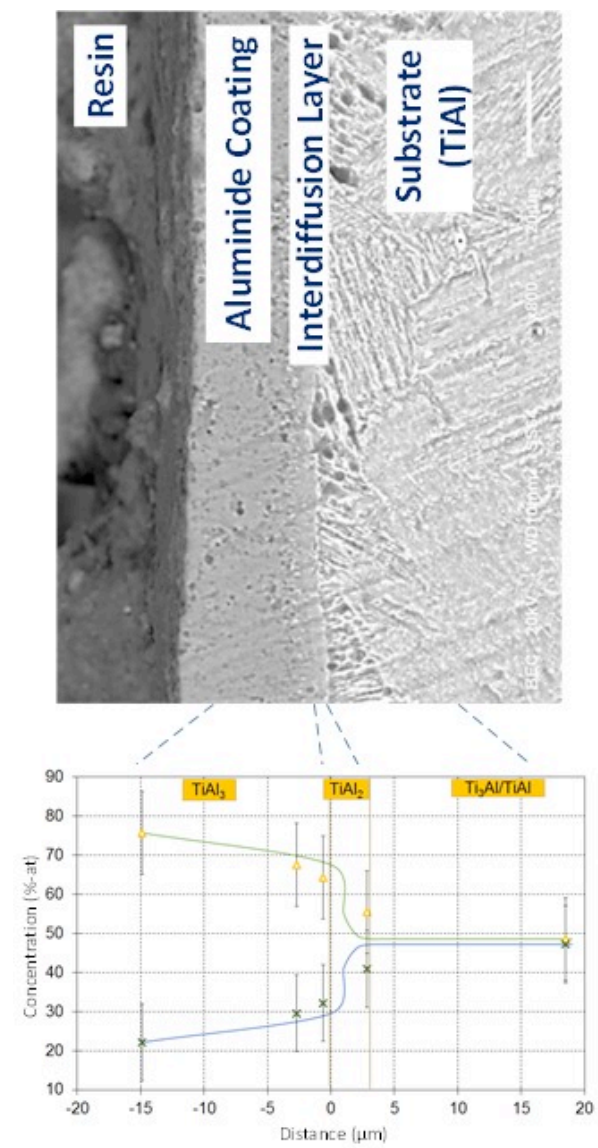

Fig. 2. Microstructure and concentration profiles of the alloy at temperature $800^{\circ} \mathrm{C}$ : simulated (line) and experiment ( $\Delta$ dan $\left.\mathrm{x}\right)$.
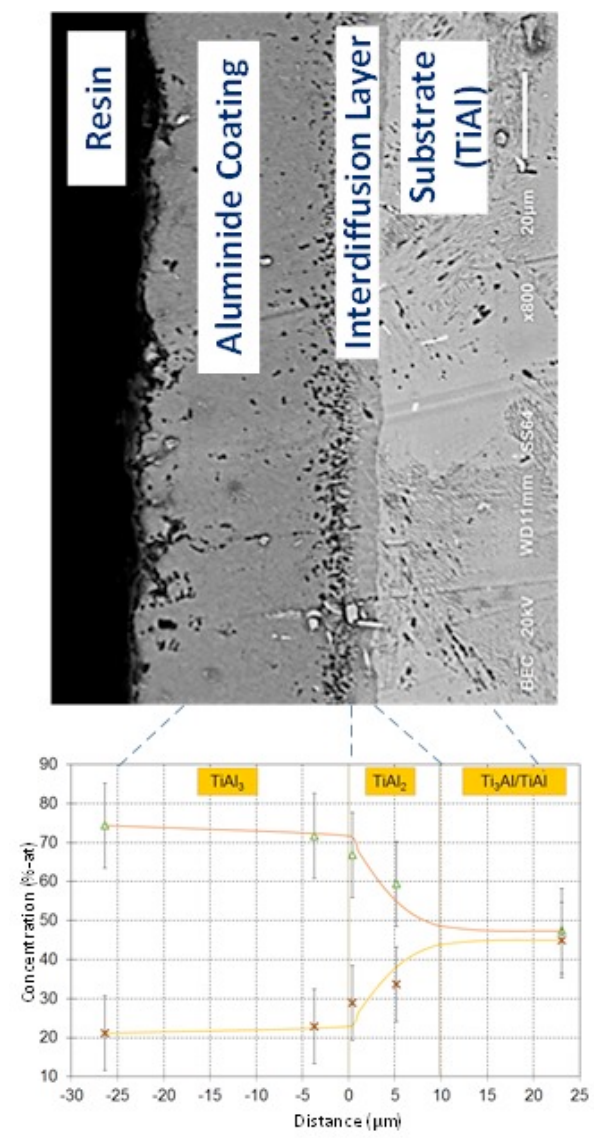

Fig. 3. Microstructure and concentration profiles of the alloy at temperature $900^{\circ} \mathrm{C}$ : simulated (line) and experiment ( $\Delta$ dan $\mathrm{x}$ ).
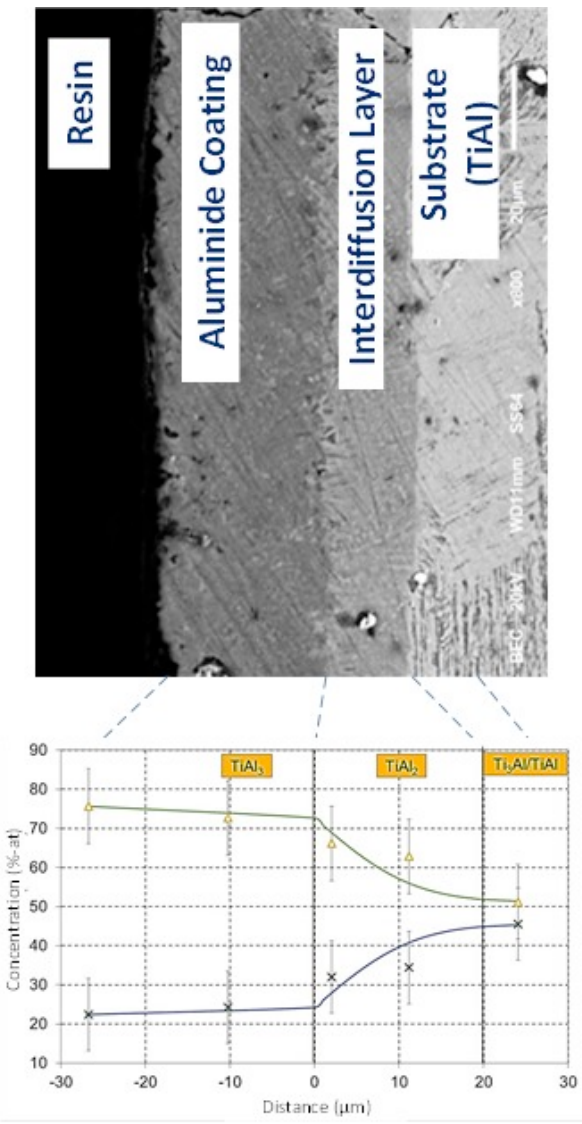

Fig. 4. Microstructure and concentration profiles of the alloy at temperature $1000^{\circ} \mathrm{C}$ : simulated (line) and experiment ( $\Delta$ dan $\mathrm{x}$ ). 
It can be seen from Fig. 2, Fig. 3, and Fig. 4 that the concentration of $\mathrm{Al}$ in the coating layer is varied between $75-78 \%$-at. It indicates that the $\mathrm{TiAl}_{3}$ phase has been formed on the coating layer as expected. While the concentration of $\mathrm{Al}$ in the interdiffusion layer is varied between $50-70 \%$-at. which is within the equilibrium region of phase TiAl and $\mathrm{TiAl}_{2}$. Therefore, it can be estimated that the phase formed in this interdiffusion layer is $\mathrm{TiAl}_{2}$ with $\mathrm{TiAl}_{2} / \gamma$-TiAl phase at the interface of interdiffusion layer-substrate and $\mathrm{TiAl}_{3} / \mathrm{TiAl}_{2}$ phase at the interface of coating-interdiffusion layer. As in the substrate, the concetration of $\mathrm{Al}$ is varied between $45-50 \%$-at. which is within the equilibrium region of dual phase $\alpha_{2}-\mathrm{Ti}_{3} \mathrm{Al} / \gamma-\mathrm{TiAl}$.

\section{CONCLUSION}

Analytical and numerical method are proposed in this study to quantitatively predict the concentration profiles between coating layer, interdiffusion layer, and the substrate of aluminide coated Ti-47Al-2Cr-2Nb-0.5Zr- $0.5 \mathrm{Y}$ intermetallic alloy. A reasonable agreement has been achieved between the experimental results and the simulated concentration profiles in each temperatures.

\section{REFERENCES}

(1) W. Voice, M. Henderson, and E. Shelton, Gamma Titanium Aluminide, Intermetallics, 3, 959-964, 2005.

(2) Clemens H, Kestrel H. Processing and Applications of Intermetallic $\gamma$-TiAl Based Alloys, Journal of Advanced Engineering Materials, 2, 551-570, 2000.

(3) M. Thomas, M.-P. Bacos, Processing and Characterization of TiAl-Based Alloys: Toward an Industrial Scale. The Onera Journal Aerospace Lab, 3, 1-8, 2011.

(4) K. Zhang, Z. Li, and W. Gao, Hot Corrosion Behaviour of Ti-Al Based Intermetallics, Mat. Let, 57, 834-843, 2002.

(5) E. Basuki, D. Prajitno, Pawawoi, Oxidation Behaviour of Aluminide Coated Ti-Al-Cr-NbZr-Y Alloys at High Temperatures, Solid State Phenomena, 227, 345-348. 2015.

(6) E. Basuki, F. Mohammad, A. Fauzi, D. Prajitno. Hot corrosion of aluminide coated TiAl-Cr-Nb-Zr-Y intermetallic alloys. Advanced Materials Research, 1112, 363-366. 2015. 